\title{
A single dose of rifampicin to prevent leprosy; quantitative analysis of impact on perception, attitudes and behaviour of persons affected, contacts and community members towards leprosy in India, Nepal and Indonesia
}

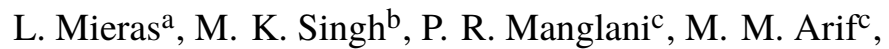

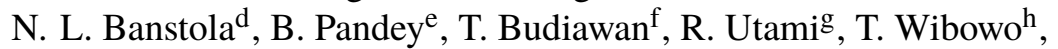
A. I. Iswandi ${ }^{i}$, R. Peters ${ }^{j} \&$ W. van Brakel ${ }^{\mathrm{a}}$

${ }^{\mathrm{a}}$ NLR, Amsterdam, Netherlands

${ }^{\mathrm{b}}$ Directorate of Medical and Health Services, Shri Vinoba Bhave Civil

Hospital Campus, Silvassa, Dadra and Nagar Haveli, India

${ }^{\mathrm{c}} N L R$ India, New Delhi, India

${ }^{\mathrm{d}}$ NLR Nepal, Kathmandu, Nepal

${ }^{\mathrm{e}}$ Leprosy Control and Disability Management Section, Ministry of Health and Population, Government of Nepal, Kathmandu, Nepal

${ }^{\mathrm{f}}$ NLR Indonesia, Jakarta, Indonesia

${ }^{\mathrm{g}}$ District Health Services, Sumenep, East Java, Indonesia

${ }^{\mathrm{h}}$ Provincial Health Services East Java, Surabaya, Indonesia

${ }^{\mathrm{i}} \mathrm{Sub}$-directorate of Direct Transmitted Tropical Disease, MoH, Jakarta,

Indonesia

${ }^{\mathrm{j}}$ Faculty of Science, Athena Institute, Vrije Universiteit, Amsterdam,

Netherlands

Submitted 24 September 2020; Accepted 29 September 2020

\begin{abstract}
Summary
Introduction: This study looked at the effect of post-exposure prophylaxis (PEP) with single-dose rifampicin (SDR) and the education given along with SDR-PEP on stakeholders' perception regarding leprosy. It is a side study of the Leprosy Postexposure Prophylaxis (LPEP) Program.

Methods: The study was done in LPEP implementation areas in India, Nepal and Indonesia. A before and after survey design was used, with qualitative and quantitative data collection methods. This paper presents the quantitative results. In each country 100 interviews were held with representatives of leprosy patients, contacts and community members, before and 1-1.5 years after starting the LPEP Program. Three tools were used: a knowledge, attitudes and practices questionnaire, EMIC community stigma scale and social distance scale (SDS).
\end{abstract}


Results: The most notable effect at follow-up was increased knowledge regarding leprosy in all stakeholder groups, especially leprosy patients. A positive effect was seen on how people think about persons affected by leprosy, reflected by the lower SDS scores in the contact groups in India and Nepal. No negative effects were found on people's perception and reported behaviour. Participants did express or perceive reluctance to disclose a person's leprosy status, but this did not negatively affect willingness to participate in the LPEP Program.

Conclusion: This study showed that implementation of SDR-PEP and accompanied education led to increased knowledge on leprosy among patients, contacts and community members and it had no negative effect on perception. SDR-PEP implementation provides an opportunity for health education, including messages to help reduce stigmatisation of persons affected by leprosy.

Keywords: Leprosy, chemoprophylaxis, health education, perception

\section{Introduction}

In the first 5 years of this millennium there has been a reduction in the number of new leprosy cases, from more than 700,000 in 2000 to around 300,000 in 2005. ${ }^{1,2}$ Since 2005 this number has been levelling off to between 208,000 and 245,000 globally per year in the last 10 years. ${ }^{3}$

Early case detection and multidrug therapy (MDT) have been the pillars of leprosy control programmes since the introduction of MDT in 1981. Though, these key elements have not been able to change the trend of ongoing transmission of M. leprae.

Until recently, sound evidence for the effectiveness of preventive measures was limited to dapsone, which had to be given for long periods of time. ${ }^{4}$ However, trials in Indonesia and Bangladesh have provided evidence of the effectiveness of a much more feasible preventive strategy: post-exposure prophylaxis (PEP) using a single dose of rifampicin (SDR). Given to contacts of new leprosy patients SDR reduced their risk of developing leprosy with around $60 \% .^{5,6}$ Subsequently, the feasibility of using SDR-PEP under operational conditions was demonstrated as an integrated part of leprosy services in several districts in Indonesia from 2012 onwards. Members of the International Federation of Anti-Leprosy Associations (ILEP) in partnership with Ministries of Health and supported by the Novartis Foundation, set up a multi-country operational research programme to evaluate the feasibility and impact of contact examination and the provision of SDR-PEP for leprosy in eight countries: Tanzania, India, Nepal, Sri Lanka, Myanmar, Indonesia, Cambodia and Brazil. This was called the leprosy post-exposure prophylaxis (LPEP) Program. ${ }^{7}$ In the LPEP Program around 20 closest contacts (family members, neighbours and social contacts) of newly detected leprosy patients received SDR-PEP. The implementation of the LPEP Program involved education of health workers in the form or a training on the effect and possible side effects of SDR-PEP (i.e., influenza-like syndromes and discoloration of urine), risk groups, contact screening, SDR-PEP administration and data collection. Leprosy patients and their contacts were given informed consent, which included information on the effect of SDR-PEP, the possible side effects, the target groups of the intervention and the right not to participate. ${ }^{7}$

A component of the feasibility of a new intervention is the perception of the stakeholders involved. For this Perception Study, which was a side study of the LPEP Program, both quantitative and qualitative methods were used. This article focusses on the analysis of the quantitative data. 
As stated in the separate publication on the analysis of the qualitative data of the perception study by Peters $e t a l{ }^{8}$ leprosy is a disease that does not only affect people physically but has social and psychological consequences as well. ${ }^{8,9}$ Lack of awareness about signs and symptoms, misconceptions about the cause and treatment of the disease and negative attitudes towards persons affected by leprosy all contribute to case detection delay and stigma. ${ }^{10-12}$ Hence, interventions that contribute to improved knowledge and a changed perception regarding leprosy can contribute to reducing stigma and early case detection.

This perception study was done in India, Nepal and Indonesia in the area where the LPEP Program was implemented. Because, introducing preventive medication for leprosy can influence the way people perceive leprosy, what they know about leprosy and their attitudes and reported behaviour towards persons affected by leprosy. As reported by Peters et al. previous studies in these countries have described the existence of stigma at various levels of intensity and in different forms, of which concerns about disclosing the disease is often a component. ${ }^{13-15}$ The aim of this study was to investigate the impact of the distribution of SDR-PEP among contacts of leprosy patients and the accompanying education on the main stakeholders' perception and knowledge levels regarding leprosy.

\section{Material and methods}

\section{STUDY DESIGN}

The perception study followed a before and after survey design. Before the start of the implementation of the LPEP Program, the perception of the respondents regarding leprosy and persons affected by the disease was documented (baseline survey). These data were compared to their perception 1-1.5 year after the start of the SDR-PEP intervention and the education that went along with the implementation (follow-up). The informed consent for the perception study, which was a sub-study of the LPEP Program, did not include information on SDR-PEP itself, it was merely information on the questionnaires and on the right not to participate in the perception study. A mixed method study design was used with a set of quantitative and qualitative instruments.

The quantitative data collection was done with standard instruments asking questions to assess knowledge, attitudes and behaviour. A short knowledge, attitudes and practices (KAP) questionnaire was used for index patients (at the time of the baseline survey these were leprosy patients eligible to be included as participants in the LPEP Program, at the time of follow-up these were patients that had been included as participants in the LPEP Program), contacts and community members. ${ }^{16}$ Two short standard instruments were used to assess attitudes and stigma regarding leprosy among contacts and community members. Both have been validated and were used in India, Nepal and Indonesia before: the EMIC (Explanatory Model Interview Catalogue) community stigma scale (15 items) and the SDS (Social Distance Scale; 7 items). ${ }^{17-19}$

The KAP questionnaire was developed to assess the knowledge, attitudes and practices of index patients, their contacts and community members regarding leprosy and SDR-PEP. ${ }^{20}$ The questionnaire consisted of yes/no questions, yes/no/don't know questions and multiple answers questions. An interview-based approach was used to fill in the questionnaires. The questionnaire started with the participant's general information and demographic data, i.e. name, age, gender, address, occupation and education. This was followed by ten core multiple and single answer questions addressing the respondents' perceptions towards leprosy, including the perceptions regarding cause and treatment of the disease and the perceptions 
Table 1. Knowledge questions in the KAP questionnaire

\begin{tabular}{ll}
\hline Knowledge questions & Correct answer ${ }^{\dagger}$ \\
\hline a. Do you know what causes leprosy?* & Germs \\
b. Do you know how leprosy is transmitted?* & Air \\
c. What are the early symptoms of leprosy?* & Skin patches or loss of sensation \\
d. Can leprosy be treated ${ }^{\dagger}$ & Yes \\
e. How can leprosy be treated?* & With medicine \\
f. Can the disability that some patients have be prevented? & Yes \\
\hline
\end{tabular}

${ }^{*}$ Multiple answer questions; ${ }^{\dagger}$ Yes/No/Don’t know questions; ${ }^{\dagger}$ at least the correct answer is given, even if combined with a wrong answer.

regarding SDR-PEP. An additional six questions were included for the index patients; two questions addressed the patients preferred name (in local language) for the disease, four questions were about their emotions after hearing the diagnosis and the emotions and attitudes of family, friends and neighbours towards leprosy.

Six questions were used to assess the knowledge level of the respondents, four multiple answer questions and two single answer questions (see Table 1). The answers considered as the correct answers were in line with the information provided to the participants in health education messages and as part of the informed consent for participation in the LPEP Program. Adequate knowledge was defined as at least five out of six questions answered correctly, moderate knowledge as three or four correct answers and inadequate knowledge as less than three correct answers.

The EMIC community stigma scale measures perceived attitudes and behaviour in the community towards affected persons. The scale covers key areas of life that may be affected by stigma, namely, concealment, avoidance, pity, shame, being made fun of, respect and marriage (prospects). ${ }^{21-23}$ During the interview, the participant was asked to respond to 15 questions, offering four response options that are valued with different scores: yes (2), possibly (1), no (0) and don't know (0). For example, Question 1: 'Would a person with leprosy try to keep others from knowing?' If the interviewee answered with 'yes', s/he scored 2 for this question. At the end of the interview, the scores of the 15 questions were summed to determine the EMIC sum score (min. 0-max. 30). A higher total score indicates that the community attitude towards persons affected by leprosy is perceived more negatively.

The SDS measures the social distance the interviewee wants to keep towards a person with a particular condition, in this case leprosy. ${ }^{24}$ It was used with an interview-based approach. The interviewer started the SDS by reading the vignette, a short description or statement of a person with leprosy (adapted to the culture of each country), followed by seven questions concerning the person in the vignette. The vignettes were gender specific. The participant responded to the seven questions by choosing one of four options scored as follows, definitely willing (0), probably willing (1), probably not willing (2) or definitely not willing (3). For example, Question 2 asks: 'How about being a worker on the same job with someone affected by leprosy?' If the participant chose 'definitely willing', s/he scored 0 for this question. After finishing the seven questions, the individual question scores were summed to determine the SDS total score (min. 0-max. 21). A higher total score indicates a person's tendency to keep social distance to persons affected by leprosy. 
Table 2. Key leprosy indicators before the start of the study; $2013^{7}$

\begin{tabular}{lccc}
\hline & $\begin{array}{c}\text { India } \\
\text { Dadra \& Nagar Haveli, } \\
\text { Union Territory }\end{array}$ & $\begin{array}{c}\text { Indonesia } \\
\text { Sumenep district, } \\
\text { East Java province }\end{array}$ & $\begin{array}{c}\text { Nepal } \\
\text { Jhapa district, } \\
\text { East Nepal }\end{array}$ \\
\hline Population (in thousands) & 374 & 1,059 & 813 \\
New case detected rate (NCDR)/10,000 & 9.8 & 4.5 & 2.7 \\
New cases with multibacillary leprosy (\%) & 23.1 & 75.8 & 57.2 \\
New cases with disability grade 2(\%) & 0.0 & 9.5 & 2.2 \\
Female (\%) among new cases & 59.2 & 48.0 & 38.0 \\
Children (\%) among new cases & 26.1 & 10.9 & 4.8 \\
\hline
\end{tabular}

\section{STUDY AREA}

The perception study was conducted in selected areas in India, Nepal and Indonesia where the LPEP Program was implemented: Dadra \& Nagar Haveli Union Territory, India; Sumenep district in East Java province, Indonesia; Jhapa district, Nepal. Table 2 provides an overview of the key leprosy-related indicators per study area before the start of the study, in 2013.

There are some big differences, namely the low multibacillary (MB) \% and disability grade 2 (DG2) \% in India compared to the other countries, as well as the high female \% and child \% in India compared to the other countries. This is probably partly explained by the fact that the leprosy control programme in Dadra \& Nagar Haveli (DNH) has a strong active case finding component; multiple active case finding campaigns are carried out annually because of which cases are found early, before nerve damage has developed. The higher female percentage in DNH may be due to the high number of female health workers and community volunteers involved in leprosy case detection.

\section{STUDY POPULATION AND SAMPLE SIZE}

The study population of the quantitative component of the study included representatives of the main stakeholders: (1) index patients; (2) contacts and (3) community members who were not contacts but who lived near the index patient. They were interviewed before and 1-1.5 year after the start of the LPEP Program.

Systematic samples were selected with a random start in the three respondent groups in all three countries. The aim was to select at least 100 persons of each group in the baseline survey, who would then be interviewed again one year after the start of the intervention to be able to do a paired analysis. This estimate was based on a validation study done in Cirebon District, Indonesia of both the EMIC and the SDS scale. ${ }^{17}$ A mean EMIC score of 15.4 with a SD of 6.5 was found. Which means a sample size of 100 persons would allow for a detection of a difference of 3 points $(10 \%)$ in EMIC scores before and after the start of the LPEP implementation (this was rounded up to allow for some loss of data).

The enrolment of index patients and their contacts was backdated to include persons diagnosed with leprosy up to two years before the start of the LPEP implementation. Community members, not defined as contacts, were eligible for enrolment in the perception study. The baseline interviews were done before people had a chance to hear about the SDR-PEP intervention.

Contacts were selected by convenience sampling, from among the group of contacts of a person affected by leprosy, i.e. household members and neighbours. These contacts were 
targeted for SDR-PEP. The respondents among the community members, not targeted for SDRPEP, were randomly selected, using convenience sampling, from among neighbours of the index patients. The minimal age for participants was $>10$ years.

\section{DATA COLLECTION AND ANALYSES}

The interview teams were formed of both female and male non-medical staff (students or research assistants) with knowledge of the cultural context of the intervention areas and proficiency in the local languages. They were all trained to use the instruments. A paper-based data collection system was used. Data were entered into an Epi Info database in India and Nepal and in an Excel file in Indonesia. Data analysis was done using Epi Info 7.2.1.0.

A demographic profile of the study sample was made using descriptive methods. Analyses were made of the KAP questionnaire and the EMIC and SDS measures comparing the different interview groups in the three countries and comparing the baseline and follow-up data using means, calculating $95 \%$ confidence intervals and performing $t$-tests and chi-square tests. To further investigate the factors influencing the differences univariate and multivariate analyses were performed, using a backward elimination procedure considering the $p$-values of the univariate analysis of the variables potentially associated with the outcome, to come to the best fit model $\left(R^{2}\right)$.

\section{ETHICAL CONSIDERATIONS}

The national leprosy control programmes of India and Nepal submitted the country-specific LPEP protocol, which included the side studies among which the perception study, to the relevant ethics committees and obtained ethical approval before the initiation of the data collection. In Indonesia the study was done under authority of the Ministry of Health. Oral or written informed consent was obtained before the start of the interviews. Consent forms had been translated into the local languages and, in case the respondent was not literate, were read out loud by the interviewer. The main LPEP operational study involved consent taking of all respondents; index patients and their contacts. The main LPEP Program consent contained information on the working of SDR-PEP and its possible side effects (i.e., influenza-like symptoms and discoloration of urine) and details on how a leprosy expert could be contacted in case of adverse events or other concerns. ${ }^{7}$ The consent of the perception study at the baseline did not contain information about the working of SDR-PEP and its possible side effects.

\section{Results}

During the baseline survey, just before the start of the LPEP implementation, and 1-1.5 year after the start of the implementation around 100 respondents were interviewed in each group. The intention was for the same respondents to be interviewed before and after the start of the intervention. This was successfully done in India with an $11 \%$ loss to follow-up in the group of index patients and a $7 \%$ and $6 \%$ loss to follow-up in the contact and community members groups respectively. In Indonesia and Nepal, the group of respondents was not the same, so no paired analysis was performed. However, the respondent groups during the baseline survey and the follow-up survey in Indonesia and Nepal were very comparable: Looking at the overall group differences, based on the chi-square test for categorical variables significant differences were only seen between the education levels in the groups of index patients and contacts in both Indonesia and Nepal and between the groups of community members in Nepal. Between 82 and 101 respondents in each group were included in the analysis (see Table 3 for an overview of the characteristics of each of the respondent groups). 
Table 3. Overview of the characteristics of the respondents in each group

\begin{tabular}{|c|c|c|c|c|c|c|}
\hline & $\begin{array}{c}\text { India } \\
\text { baseline } \\
\text { May } 2015\end{array}$ & $\begin{array}{c}\text { India } \\
\text { follow-up } \\
\text { June } 2016\end{array}$ & $\begin{array}{c}\text { Indonesia } \\
\text { baseline } \\
\text { Feb } 2015\end{array}$ & $\begin{array}{l}\text { Indonesia } \\
\text { follow-up } \\
\text { July } 2016\end{array}$ & $\begin{array}{c}\text { Nepal } \\
\text { baseline } \\
\text { May } 2015\end{array}$ & $\begin{array}{c}\text { Nepal } \\
\text { follow-up } \\
\text { May } 2016\end{array}$ \\
\hline Number of Index patients & 92 & 82 & 101 & 90 & 100 & 100 \\
\hline Age; average & 40 & 42 & 42 & 44 & 37 & 39 \\
\hline$(\min -\max )$ & $(14-75)$ & $(15-76)$ & $(16-85)$ & $(18-100)$ & $(12-69)$ & $(13-69)$ \\
\hline \#Female/\#Male & $52 / 40$ & $46 / 36$ & $50 / 51$ & $44 / 46$ & $44 / 56$ & $50 / 50$ \\
\hline \multicolumn{7}{|l|}{ Education } \\
\hline No (formal) education $\%$ & $85 \%$ & $85 \%$ & $28 \%$ & $40 \%$ & $40 \%$ & $47 \%$ \\
\hline Primary school \% & $9 \%$ & $10 \%$ & $44 \% *$ & $26 \% *$ & $28 \%$ & $39 \%$ \\
\hline Secondary school \% & $5 \%$ & $2.5 \%$ & $23 \%$ & $21 \%$ & $24 \% *$ & $13 \% *$ \\
\hline Higher education $\%$ & $1 \%$ & $2.5 \%$ & $5 \%$ & $3 \%$ & $8 \% *$ & $1 \% *$ \\
\hline Number of Contacts & 90 & 84 & 101 & 100 & 99 & 100 \\
\hline Age; average & 38 & 39 & 38 & 43 & 37 & 37 \\
\hline$(\min -\max )$ & $(18-67)$ & $(16-68)$ & $(17-70)$ & $(12-75)$ & $(13-82)$ & $(13-68)$ \\
\hline \# Female/\# Male & $45 / 45$ & $40 / 44$ & $44 / 57$ & $58 / 42$ & $66 / 33$ & $63 / 37$ \\
\hline \multicolumn{7}{|l|}{ Education } \\
\hline No (formal) education $\%$ & $73 \%$ & $73 \%$ & $17 \% *$ & $31 \% *$ & $44 \%$ & $48 \%$ \\
\hline Primary school \% & $17 \%$ & $17 \%$ & $44 \%$ & $39 \%$ & $29 \%$ & $35 \%$ \\
\hline Secondary school \% & $7 \%$ & $7 \%$ & $37 \%$ & $27 \%$ & $21 \%$ & $17 \%$ \\
\hline Higher education $\%$ & $3 \%$ & $3 \%$ & $2 \%$ & $3 \%$ & $6 \% *$ & $0 \% *$ \\
\hline $\begin{array}{l}\text { Number of Community } \\
\text { members }\end{array}$ & 94 & 88 & 101 & 97 & 100 & 100 \\
\hline Age; average & 37 & 39 & 43 & 45 & 35 & 37 \\
\hline$(\min -\max )$ & $(15-76)$ & $(16-77)$ & $(19-80)$ & $(20-81)$ & $(12-64)$ & $(12-70)$ \\
\hline \# Female/\# Male & $40 / 54$ & $38 / 50$ & $21 / 80$ & $20 / 77$ & $43 / 57$ & $42 / 58$ \\
\hline \multicolumn{7}{|l|}{ Education } \\
\hline No (formal) education \% & $55 \%$ & $57 \%$ & $11 \%$ & $11 \%$ & $23 \% *$ & $43 \% *$ \\
\hline Primary school \% & $30 \%$ & $27 \%$ & $42 \%$ & $45 \%$ & $23 \%$ & $31 \%$ \\
\hline Secondary school \% & $12 \%$ & $13 \%$ & $34 \%$ & $37 \%$ & $39 \% *$ & $24 \% *$ \\
\hline Higher education $\%$ & $3 \%$ & $3 \%$ & $13 \%$ & $7 \%$ & $15 \% *$ & $2 \% *$ \\
\hline
\end{tabular}

${ }^{*}$ Significantly different $(p<0.05)$ based on the chi-square test.

\section{KNOWLEDGE}

All interviewed groups (index patients, contacts and community members) in all three countries significantly improved their knowledge level regarding leprosy 1-1.5 year after the start of the LPEP implementation (see Table 4). Knowledge levels had especially gone up in the index patient groups.

One of the six knowledge questions 'Do you know what causes leprosy?' showed that there are different misconceptions in the three countries around the reason why people develop leprosy. The percentage of people answering that leprosy is caused by immoral conduct, impure blood, punishment for sins, unclean environment, witchcraft or food or drinks ${ }^{1}$ varied in the different groups between 0 and $8 \%$ in India, while this was 31-54\% in Indonesia and $13-34 \%$ in Nepal. The highest percentage (54\%) was seen among contacts in Indonesia one year after the start of the intervention (compared to $39 \%$ at the time of the baseline survey).

To get a better understanding of the factors associated with higher knowledge levels (number of correct answers) multivariate linear regression analysis was performed (see Table 5).

\footnotetext{
${ }^{1}$ Food or drinks were only reported as cause by respondents in Nepal.
} 
Table 4. Percentage of respondents with adequate knowledge at the time of baseline and follow-up

\begin{tabular}{|c|c|c|c|c|c|c|}
\hline Adequate knowledge* & $\begin{array}{l}\text { Index patients } \\
\%(95 \% \mathrm{CI})\end{array}$ & $N$ & $\begin{array}{c}\text { Contacts } \\
\%(95 \% \mathrm{CI})\end{array}$ & $N$ & $\begin{array}{c}\text { Community members } \\
\%(95 \% \mathrm{CI})\end{array}$ & $N$ \\
\hline \multicolumn{7}{|l|}{ India } \\
\hline baseline & $22 \%(14-32)$ & 92 & $9 \%(4-17)$ & 90 & $17 \%(10-26)$ & 94 \\
\hline follow-up & $68 \%(57-78)$ & 82 & $33 \%(23-45)$ & 84 & $38 \%(27-49)$ & 88 \\
\hline$p$-value & $p<0.001$ & & $p<0.001$ & & $p=0.002$ & \\
\hline \multicolumn{7}{|l|}{ Indonesia } \\
\hline baseline & $8 \%(4-15)$ & 101 & $13 \%(7-21)$ & 101 & $10 \%(5-18)$ & 101 \\
\hline follow-up & $37 \%(27-48)$ & 90 & $29 \%(20-39)$ & 100 & $38 \%(29-49)$ & 97 \\
\hline$p$-value & $p<0.001$ & & $p=0.005$ & & $p<0.001$ & \\
\hline \multicolumn{7}{|l|}{ Nepal } \\
\hline baseline & $8 \%(4-15)$ & 100 & $6 \%(2-13)$ & 99 & $4 \%(1-10)$ & 100 \\
\hline follow-up & $44 \%(34-54)$ & 100 & $39 \%(29-49)$ & 100 & $29 \%(20-39)$ & 100 \\
\hline$p$-value & $p<0.001$ & & $p<0.001$ & & $p<0.001$ & \\
\hline
\end{tabular}

${ }^{*}$ Adequate knowledge $=5$ or $6 / 6$ correct answers.

A backward elimination procedure was followed considering the $p$-values to come to a 'best fit' model (based on $R^{2}$ ). A good model fit was found for the index patients in all three countries, the contacts in India and Indonesia and the community members in Indonesia. The analysis showed that the knowledge level in these groups was not only determined by the timing in relation to the intervention (baseline versus one year after the intervention) but also by level of education, existing misconceptions about the cause of leprosy, gender and age. In India higher age was associated with lower knowledge levels, while in Indonesia and Nepal education played a role: higher education was associated with higher knowledge levels. In India the mean knowledge level was higher among female index patients than male index patients (see Table 5).

\section{ATTITUDES AND PRACTICES OF INDEX PATIENTS}

As part of the KAP questionnaire the index patients were asked four additional questions regarding attitudes and practices. There were no significant differences between the answers to these questions before and after the start of the intervention.

Index patients in Indonesia were less likely to respond positively to the question 'Would you prefer to keep people from knowing that you have leprosy?' compared to the index patients in India and Nepal. In Indonesia $20 \%$ of the index patients answered that they would prefer to keep people from knowing they have leprosy 1-1.5 year after the start of the implementation of LPEP, while this was $59 \%$ and $71 \%$ in India and Nepal respectively.

The question 'Do your neighbours, colleagues or others in your community have less respect for you because of your illness?' was answered positively in Indonesia by 17\%, in Nepal by $21 \%$ and in India by only $2 \%$ of the index patients. It is noteworthy that $51 \%$ of the index patients in India answered this question with 'not sure', while this was $25 \%$ in both Indonesia and Nepal.

The highest percentage answering 'Yes' to the questions 'Have you decided by yourself to stay away from work or social group?' and 'Would some people refuse to visit your home even after you have been treated?' were the index patients in Indonesia (13\% and 14\%). The index patients in India were more likely to answer these questions with 'not sure' $(47 \%$ and $44 \%)$. 
Table 5. Correlations between knowledge level and other variables* in the pooled dataset (baseline and follow-up)

\begin{tabular}{|c|c|c|c|c|}
\hline & Variable & Coefficient & Standard error & $p$-value \\
\hline \multicolumn{5}{|l|}{ Index patients India $n=174$} \\
\hline \multirow{5}{*}{$\begin{array}{l}\text { This model explained } 35 \% \text { of the } \\
\text { variability }(R \text {-squared }=0.35) .\end{array}$} & One year follow-up/Baseline & 1.271 & 0.154 & 0.000 \\
\hline & Misconceptions about the cause & -1.125 & 0.513 & 0.030 \\
\hline & Gender $(\mathrm{M} / \mathrm{F})$ & -0.379 & 0.154 & 0.014 \\
\hline & Age & -0.025 & 0.005 & 0.000 \\
\hline & Constant & 4.936 & 0.254 & 0.000 \\
\hline \multicolumn{5}{|l|}{ Index patients Indonesia $n=191$} \\
\hline \multirow{3}{*}{$\begin{array}{l}\text { This model explained } 18 \% \text { of the } \\
\text { variability }(R \text {-squared }=0.18)\end{array}$} & Baseline/One year follow-up & -0.787 & 0.156 & 0.000 \\
\hline & Completed sec. school or higher & 0.693 & 0.175 & 0.000 \\
\hline & Constant & 3.904 & 0.122 & 0.000 \\
\hline \multicolumn{5}{|l|}{ Index patients Nepal $n=200$} \\
\hline \multirow{3}{*}{$\begin{array}{l}\text { This model explained } 32 \% \text { of the } \\
\text { variability }(R \text {-squared }=0.32) \text {. }\end{array}$} & One year follow-up/Baseline & 0.974 & 0.104 & 0.000 \\
\hline & Completed sec. school or higher & 0.521 & 0.124 & 0.000 \\
\hline & Constant & 3.443 & 0.082 & 0.000 \\
\hline \multicolumn{5}{|l|}{ Contacts India $n=174$} \\
\hline & One year follow-up/Baseline & 1.015 & 0.152 & 0.000 \\
\hline This model explained $25 \%$ of the & Gender $(\mathrm{M} / \mathrm{F})$ & 0.316 & 0.154 & 0.041 \\
\hline \multirow[t]{2}{*}{ variability $(R$-squared $=0.25)$} & Age & -0.017 & 0.006 & 0.002 \\
\hline & Constant & 3.623 & 0.239 & 0.000 \\
\hline \multicolumn{5}{|l|}{ Contacts Indonesia $n=201$} \\
\hline \multirow{4}{*}{$\begin{array}{l}\text { This model explained } 15 \% \text { of the } \\
\text { variability }(R \text {-squared }=0.15) .\end{array}$} & Baseline/One year follow-up & -0.619 & 0.151 & 0.000 \\
\hline & Misconceptions about the cause & 0.414 & 0.154 & 0.008 \\
\hline & Completed sec. school or higher & 0.353 & 0.160 & 0.029 \\
\hline & Constant & 3.601 & 0.135 & 0.000 \\
\hline \multicolumn{5}{|l|}{ Community Indonesia $n=198$} \\
\hline \multirow{4}{*}{$\begin{array}{l}\text { This model explained } 24 \% \text { of the } \\
\text { variability }(R \text {-squared }=0.24) .\end{array}$} & Baseline/One year follow-up & -0.782 & 0.186 & 0.000 \\
\hline & Misconceptions about the cause & 0.873 & 0.190 & 0.000 \\
\hline & Completed sec. school or higher & 0.841 & 0.188 & 0.000 \\
\hline & Constant & 3.067 & 0.170 & 0.000 \\
\hline
\end{tabular}

*Age; gender; education level; misconceptions about the cause.

CONTACTS' AND COMMUNITY MEMBERS' ATTITUDES AND BEHAVIOUR TOWARDS PERSONS AFFECTED BY LEPROSY

The mean EMIC total score varied from 3.0 in the contact group in India to 12.9 in the contact group in Nepal during the baseline survey (see Table 6). This indicates a difference in perceived attitude and behaviour in the LPEP implementation areas in the different countries. The mean SDS total score varied from 4.8 in the contact group in Nepal to 9.7 among the community members in India during the baseline survey, indicating a variety in people's tendency to keep social distance to persons affected by leprosy in the three countries (see Table 6).

In both the contacts and community members groups in Nepal a decrease is seen in both the mean SDS and EMIC sum score. While in India a decrease is only seen in the mean SDS sum score in the contact group; from 8.9 at baseline to 2.5 one year after the start of the LPEP intervention. The mean EMIC sum scores in India were already quite low before the intervention. No changes were seen in Indonesia between the scores during the baseline survey and one year after the start of the LPEP intervention. The mean SDS sum scores of the contacts in India and Nepal before and after the intervention indicate a positive change in their attitude towards persons affected by leprosy. The mean EMIC sum score, reflecting both perceived attitude and behaviour in relation to persons affected by leprosy, did not change 
Table 6. Overview mean total scores SDS, EMIC in contacts and community members, baseline vs. follow-up

\begin{tabular}{|c|c|c|c|c|c|c|}
\hline \multirow{2}{*}{$\begin{array}{l}\text { SDS and EMIC* } \\
\text { mean total scores }\end{array}$} & \multicolumn{2}{|c|}{ Contacts \% $(95 \% \mathrm{CI})$} & \multirow[t]{2}{*}{$N$} & \multicolumn{2}{|c|}{ Community members \% (95\% CI) } & \multirow[t]{2}{*}{$N$} \\
\hline & SDS mean & EMIC mean & & SDS mean & EMIC mean & \\
\hline \multicolumn{7}{|l|}{ India } \\
\hline Baseline & $8.9(7.5-10.3)$ & $3.0(2.1-3.9)$ & 90 & $9.7(8.5-10.9)$ & $4.0(2.7-5.2)$ & 94 \\
\hline $\begin{array}{c}\text { Follow-up } \\
p \text {-value }\end{array}$ & $\begin{array}{c}2.5(1.9-3.1) \\
p<0.001\end{array}$ & $\begin{array}{c}3.2(2.8-3.6) \\
p=0.674\end{array}$ & 84 & $\begin{array}{c}8.3(7.2-9.4) \\
p=0.082\end{array}$ & $\begin{array}{c}4.4(2.8-5.3) \\
p=0.932\end{array}$ & 88 \\
\hline \multicolumn{7}{|l|}{ Indonesia } \\
\hline Baseline & $7.4(6.5-8.3)$ & $9.9(8.8-11.1)$ & 101 & $6.8(5.8-7.8)$ & $10.0(8.8-11.2)$ & 101 \\
\hline $\begin{array}{l}\text { Follow-up } \\
p \text {-value }\end{array}$ & $\begin{array}{c}7.2(6.2-8.1) \\
p=0.730\end{array}$ & $\begin{array}{c}10.1(9.0-11.3) \\
p=0.821\end{array}$ & 100 & $\begin{array}{c}7.6(6.7-8.5) \\
p=0.217\end{array}$ & $\begin{array}{c}10.5(9.7-11.4) \\
p=0.481\end{array}$ & 97 \\
\hline \multicolumn{7}{|l|}{ Nepal } \\
\hline Baseline & $4.8(3.7-5.8)$ & $12.9(11.6-14.2)$ & 99 & $5.1(4.1-6.1)$ & $9.7(8.6-10.9)$ & 100 \\
\hline $\begin{array}{c}\text { Follow-up } \\
p \text {-value }\end{array}$ & $\begin{array}{c}3.1(2.2-3.9) \\
p=0.017\end{array}$ & $\begin{array}{c}10.8(9.1-12.5) \\
p=0.060\end{array}$ & 100 & $\begin{array}{c}3.7(2.6-4.7) \\
p=0.052\end{array}$ & $\begin{array}{c}8.3(7.2-9.3) \\
p=0.067\end{array}$ & 100 \\
\hline
\end{tabular}

$\mathrm{EMIC}=$ perceived attitude and behaviour; SDS = attitudes towards persons affected by leprosy.

much. There are no clear differences in the mean EMIC or SDS total scores between contacts and community members, except for the difference between the mean SDS total score of the contacts $(2.5$ (95\% CI 1.9-3.1)) and community members $(8.3$ (95\% CI 7.2-9.4)) in India, at the time of follow-up.

The questions that invariably scored highest were questions related to marriage: 'Would having leprosy cause problems in ongoing marriage?'; 'Would having leprosy cause a problem to get married?' in the EMIC scale and 'How about having someone with leprosy marry one of your children?' in the SDS scale. Other questions that scored high in most groups were: 'Would a person with leprosy try to keep others from knowing?' in the EMIC scale, and 'How about having someone with leprosy as a caretaker for your children for a couple of hours?'

\section{Discussion}

The findings presented in this paper are in line with the conclusion from an earlier publication focusing on the analysis of the qualitative data collected in this study. Peters et al. concluded that the implementation of the LPEP Program was perceived positively and no negative effects were reported. ${ }^{8}$ The quantitative data presented in this article showed a positive change in knowledge regarding leprosy, which had increased in all respondent groups (index patients, contacts and community members) in all three countries 1-1.5 year after the start of SDRPEP administration. The increased knowledge was most apparent in the patient group. Index patients and contacts in Indonesia and Nepal and community members in Nepal had lower education levels at the time of follow-up (Table 3), which makes the increase in knowledge levels on leprosy even more noteworthy.

Misconceptions about the cause of leprosy were found to be especially common, which is in line with findings in previous studies. ${ }^{20,25}$ Remarkably, the highest percentage (54\%) was seen among contacts in Indonesia at the time of follow-up (compared to 39\% at the time of the baseline survey). Further improving knowledge regarding leprosy in general and in particular the cause of the disease should be embedded in health education messages as part of the continued implementation of SDR-PEP, using a context specific and targeted approach. ${ }^{20,26}$ 
Peter et al. saw no effect on the way leprosy or persons affected by leprosy were perceived, though respondents did identify some positive changes that might occur because of the recognised importance of reducing the risk of developing leprosy among patients as well as their contacts. These positive changes were confirmed by the analysis of the quantitative data. The lower mean SDS total scores, at the time of follow-up in the contact groups in India and Nepal reflect a positive effect on how people think about persons affected by leprosy and some effect was seen on attitudes towards persons affected by leprosy. A remarkable variation was seen in the mean EMIC total score which varied from 3.0 in the contact group in India to 12.9 in the contact group in Nepal during the baseline survey. It shows that perceived attitude and behaviour varies in different socio-economic contexts. ${ }^{27}$ A possible explanation for the lower EMIC scores in India is that the people living in Dadra and Nagar Haveli, the Union Territory in which the LPEP Program was implemented in India, are known to have a high level of trust in the health services. ${ }^{28}$ In Nepal and Indonesia, the static EMIC sum score over time could possibly be explained by the fact that attitude changes, based on changes in fear, for example, which are reflected by the mean SDS total score, are seen before changes in patterns of behaviour can be noticed. The difference in perspective may also be important. The EMIC reflects perceived community attitudes and behaviour which is likely to change more slowly than personal fears and attitudes (SDS).

Community members generally score higher on perceived stigma than closer contacts of persons affected by leprosy, as was also the case in this study. ${ }^{19}$

In other leprosy perception studies done in Indonesia and India similar mean EMIC and SDS total scores were found as in this study at baseline, except for the lower EMIC scores in India. ${ }^{16,20}$ The mean EMIC sum score in both studies was between 12.9 and 16.2 and the SDS scores were between 7.0 and 9.0, for contacts as well as for community members.

In the qualitative analysis by Peters et al. it was found that some index patients had concerns about disclosing their disease status. This was confirmed by the quantitative data. All respondent groups, index patients as well as contacts and community members, expressed or perceived reluctance to disclose a person's leprosy status as one of the main concerns. However, this did not negatively affect people's willingness to participate in the LPEP Program enabling close contacts to reduce their risk of developing leprosy; results of the LPEP Program show that less than $1 \%$ of the index patients refused to participate. ${ }^{29}$ Similar results were seen in India, Indonesia and Nepal. The high percentage of participants that expressed concerns about disclosure does ask for more research into reasons why and how disclosure concerns differ in different contexts of PEP administration. Also, alternative ways to implement SDRPEP that do not require disclosure, such as mass drug administration, should be studied.

Other common concerns were about marriage involving a person affected by leprosy. In the answers given to questions related to marriage negative perceptions and attitudes are often reflected. ${ }^{16,20}$

One of the findings was different: while the qualitative analysis indicated that the desire to conceal the disease appeared to be higher in Indonesia than in India and Nepal, in this quantitative study it was found that a smaller proportion of index patients preferred to hide their disease status in Indonesia than in Nepal and India. There is no explanation for this finding, but it underlines the importance of collecting both quantitative and qualitative data on a given topic, since results are not always generalisable.

SDR-PEP administration requires training of health workers and volunteers and an intensification of the interaction between health workers and leprosy patients and their contacts, which may be a challenge in contexts where health workers have responsibilities across multiple 
health programmes. The intervention reduces the risk of developing leprosy in the group most at risk of developing the disease. It is also an excellent opportunity for additional health education messages to stimulate people to report with early signs and symptoms and to reduce stigmatisation of people affected by leprosy. In the analysis of the qualitative data it was found that the information regarding SDR-PEP was not always clearly understood. Some respondents thought that the single dose of rifampicin would completely protect them against developing the disease. The quantitative analysis showed that knowledge regarding leprosy did improve, so specific efforts should be made to ensure that clear messages about the preventive effect of SDR-PEP are embedded in the information provided.

\section{Conclusion}

The quantitative component of the LPEP perception study showed that no negative effects were observed 1-1.5 year after SDR-PEP administration was introduced, which is in line with the findings of the qualitative component of the LPEP perception study. The LPEP Program, in which training of health workers and informed consent giving of patients and their contacts were embedded, had a positive effect on the knowledge regarding leprosy in general and neutral or positive effect on the attitudes towards persons affected by leprosy of contacts and community members in Nepal and contacts in India. Research is needed to find approaches to overcome disclosure concerns regarding the identity of the leprosy patient. Attention should be given to providing good quality training and information when implementing SDR-PEP. Contact examination and SDR-PEP administration provide an opportunity for health education in the community in which specific messages to reduce stigmatisation and discrimination should be taken up.

\section{Acknowledgements}

We thank the Novartis Foundation for funding the LPEP Program and the LPEP teams in India, Nepal and Indonesia for conducting the study. We thank Ms. Anneke Taal for developing the protocol for this study and Ms. Anna van 't Noordende for her input in the analysis. We are especially grateful for the research assistants conducting the interviews, collecting the data and all participants in the studies.

\section{References}

1 WHO | 4 January 2002, Vol 77, 1 (pp 1-8). Available from: https://www.who.int/wer/2002/wer7701/en/ [Internet] [cited $2020 \mathrm{Feb} 19]$.

2 World Health Organization. WHO | Weekly Epidemiological Record, 2009; 84(33): 333-340. Available from: http://www.who.int/wer [cited 2017 Dec 22].

3 World Health Organization. WHO | Weekly Epidemiological Record, 31 August 2018, vol. 93, 35 (pp. 444-456). WHO. 2018.

4 Smith CM, Smith WCS. Chemoprophylaxis is effective in the prevention of leprosy in endemic countries: a systematic review and meta-analysis. J Infect, 2000; 41(2): 137-142.

5 Bakker MI, Hatta M, Kwenang A, Van Benthem BHB, Van Beers SM, Klatser PR et al. Prevention of leprosy using rifampicin as chemoprophylaxis. Am J Trop Med Hyg, 2005; 72(4): 443-448, Available from: http://ww w.ncbi.nlm.nih.gov/pubmed/15827283 [Internet] [cited 2017 May 7].

6 Moet FJ, Pahan D, Oskam L, Richardus JH. Effectiveness of single dose rifampicin in preventing leprosy in close contacts of patients with newly diagnosed leprosy: cluster randomised controlled trial. BMJ, 2008; 336(7647): 761-764.

7 Barth-Jaeggi T, Steinmann P, Mieras L, van Brakel WH, Richardus JH, Tiwari A et al. Leprosy Post-Exposure Prophylaxis (LPEP) programme: study protocol for evaluating the feasibility and impact on case detection rates of contact tracing and single dose rifampicin. BMJ Open, 2016; 6(11): e013633. Available from: http://dx.doi. org/ [Internet]. 
8 Peters RMH, Mieras L, Subedi M, Apte H, Koesbardiati T, Banstola N, Das S, van Brakel WH. A single dose of rifampicin to prevent leprosy: Qualitative analysis of perceptions of persons affected, contacts, community members and health professionals towards chemoprophylaxis and the impact on their attitudes in India, Nepal and Indonesia. Lepr Rev, 2018; 89(4): 335-352, Available from: https://www.scopus.com/inward/record.uri?ei d=2-s2.0-85052225077\&partnerID=40\&md5=bb6dd2b684995d9837a07118e11a8738 [Internet].

9 van Brakel WH, Sihombing B, Djarir H, Beise K, Kusumawardhani L, Yulihane R et al. Disability in people affected by leprosy: the role of impairment, activity, social participation, stigma and discrimination. Glob Health Action, 2012; 5(1): 18394. Available from: https://www.tandfonline.com/doi/full/10.3402/gha.v5i0.183 94 [Internet] [cited 2017 Oct 23].

10 Nicholls PG, Wiens C, Smith WCS. Delay in presentation in the context of local knowledge and attitude towards leprosy - the results of qualitative fieldwork in Paraguay. Int J Lepr Other Mycobact Dis, 2003; 71(3): 198-209, Available from: http://www.ncbi.nlm.nih.gov/pubmed/14608815 [Internet] [cited 2020 Feb 11].

11 Nicholls PG, Ross L, Smith WCS. Promoting early detection in leprosy - a literature review to identify proven and potential interventions addressing patient-related delay. Lepr Rev, 2006; 77: 298-310, Available from: h ttps://pdfs.semanticscholar.org/e248/37aa82ec4eda9f1d584964aa686212029f8f.pdf [Internet] [cited 2020 Feb $11]$.

12 Subedi M, Engelbrektsson U-B. Factors contributing to delay in diagnosis and start of treatment of leprosy: analysis of help-seeking narratives from a community study in dang district. Dhaulagiri J Sociol Anthropol, 2018; 12: 11-17.

13 Thilakavathi S, Manickam P, Mehendale SM. Awareness, social acceptance and community views on leprosy and its relevance for leprosy control, Tamil Nadu. Indian J Lepr, 2012; 84(3): 233-240.

14 Peters RMH, Hofker ME, Zweekhorst MBM, van Brakel WH, Bunders-Aelen JGF. Narratives around concealment and agency for stigma-reduction: a study of women affected by leprosy in cirebon district, Indonesia. https://dcidj.org/articles/abstract/10.5463/dcid.v25i4.389/.

15 Heijnders ML. The dynamics of stigma in Leprosy 1. Int J Lepr, 72: Available from: http://ila.ilsl.br/pdfs/v72n 4a03.pdf [Internet] [cited 2020 Feb 11].

16 Peters RMH, Dadun ZMBM, Bunders JFG, van Brakel WH. A cluster-randomized controlled intervention study to assess the effect of a contact intervention in reducing leprosy-related stigma in Indonesia. PLoS Negl Trop Dis, 2015; 9(10): e0004003. Phillips RO, editor. Available from: http://dx.plos.org/10.1371/journal.pntd.00040 03 [Internet] [cited 2017 Oct 23].

17 Peters RMH, Van Brakel WH, Zweekhorst MBM, Damayanti R, Bunders JFG et al. The cultural validation of two scales to assess social stigma in leprosy. PLoS Negl Trop Dis, 8(11): e3274.

18 Rensen C, Bandyopadhyay S, Gopal PK, Van Brakel WH. Measuring leprosy-related stigma - a pilot study to validate a toolkit of instruments. Disabil Rehabil, 2011; 33(9): 711-719, Available from: http://www.tandfonli ne.com/doi/full/10.3109/09638288.2010.506942 [Internet] [cited 2019 Apr 26].

19 Adhikari B, Shrestha K, Kaehler N, Raut S, Chapman RS. Community attitudes towards leprosy affected persons in Pokhara municipality of western Nepal. J Nepal Health Res Counc, 2013; 11(25): 264-268, Available from: http://www.jnhrc.com.np/index.php/jnhrc/article/view/402 [Internet] [cited 2019 Apr 26].

20 van 't Noordende AT, Korfage IJ, Lisam S, Arif MA, Kumar A, van Brakel WH. The role of perceptions and knowledge of leprosy in the elimination of leprosy: a baseline study in Fatehpur district, northern India. PLoS Negl Trop Dis, 2019; 13(4): e0007302. Poonawala H, editor. Available from: http://dx.plos.org/10.1371/journa 1.pntd.0007302 [Internet] [cited 2019 Dec 22].

21 Van Brakel WH. Measuring health-related stigma-a literature review. Psychol Health Med, 2006; 11: 307-334, Available from: http://www.ncbi.nlm.nih.gov/pubmed/17130068 [Internet] [cited 2017 Dec 22].

22 Weiss MG, Doongaji DR, Siddhartha S, Wypij D, Pathare S, Bhatawdekar M et al. The Explanatory Model Interview Catalogue (EMIC). Contribution to cross-cultured research methods from a study of leprosy and mental health. Br J Psychiatry, 1992; 160(June): 819-830.

23 Weiss M. Explanatory Model Interview Catalogue (EMIC): framework for comparative study of illness. Transcult Psychiatry, 1997; 34(2): 235-263, Available from: https://journals.sagepub.com/doi/abs/10.1177/1 36346159703400204 [Internet] [cited 2020 Feb 1].

24 Link BG, Cullen FT, Frank J, Wozniak JF. The social rejection of former mental patients: understanding why labels matter. Am J Sociol, 1987; 92(6): 1461-1500.

25 Sermrittirong S, Brakel W, Rodchan S, Nuncho S, Bunders-Aelen J. Assessing the attitudes and perceptions of community members and health workers regarding leprosy stigma. Int J Trop Dis Heal, 2015; 5(1): 1124, Available from: https://www.leprosy-information.org/resource/assessing-attitudes-and-perceptions-commu nity-members-and-health-workers-regarding-leprosy [Internet] [cited 2020 Feb 11].

26 District C, Brakel V. Community stigma and desired social distance towards people affected by leprosy in Community stigma and desired social distance towards people affected by leprosy in Chandauli District, India. 2019; Available from: https://www.leprosy-information.org/resource/community-stigma-and-desired-social-di stance-towards-people-affected-leprosy-chandauli [cited 2020 Feb 11]. 
27 Sermrittirong S, Van Brakel WH. Stigma in leprosy: concepts, causes and determinants. Lepr Rev, 2014; 85(1): 36-47, Available from: http://www.ncbi.nlm.nih.gov/pubmed/24974441 [Internet] [cited 2018 May 1].

28 Apte H, Chitale M, Das S, Manglani PR, Mieras L. Acceptability of contact screening and single dose rifampicin as chemoprophylaxis for leprosy in Dadra and Nagar Haveli, India. Lepra, 28 Middlebrgh ....

29 Richardus $\mathrm{JH}$, et al. Leprosy post-exposure prophylaxis with single-dose rifampicin (LPEP): an international feasibility programme. Lancet Glob Health, 2020; https://doi.org/10.1016/S2214-109X(20)30396-X. 